15. Pirnie B., O'connell E. Counterinsurgency in Iraq (2003-2006). RAND Corporation, 2008. Vol. 2.

16. Rabasa A. Money in the bank: lessons learned from past counterinsurgency (coin) operations. RAND Corporation, 2007.

17. Jones S.G. Counterinsurgency in Afghanistan: RAND counterinsurgency study. Vol. 4. RAND Corporation, 2008. Vol. 4.

18. Rosenau W., Long F. The Phoenix Program and Contemporary Counterinsurgency. RAND Corporation: Santa Monica, 2009.

19. Hack K. The Malayan emergency as counterinsurgency paradigm // Journal of strategic studies. 2009. Vol. 32 (3). P. 383-414.
20. Wm. Roger Louis. The Dissolution of the British Empire in the Era of Vietnam. The American Historical Review, Vol. 107, № 1 (February 2002). P. 1-2521.

21. Hoffman, Bruce and Jennifer Taw, defense policy and low-intensity conflict: the development of britain's «small wars» doctrine during the 1950s, Santa Monica, calif.: RAND Corporation, r-4015-a, 1991.

22. The Harry S. Truman Library and Museum. Oral History Interview with John F. Cady Athens, Ohio July 31, 1974 by Richard D. McKinzie. P. 66.

23. Бревдон П. Упадок и разрушение Британской империи. 1781-1997. М.: АСТ, 2010. 957 с.

Исследование выполнено за счет гранта Российского научного фонда (проект № 17-78-20029).

\title{
THE «BRITISH WAY» OF COUNTERINSURGENCY STRUGGLE: RAND, DECOLONIZATION AND «EMERGENCY» IN MALAYA (1948-1960)
}

(C) 2018

Lyozin Alexander Ivanovich, student of History Faculty

Nesterov Dmitriy Aleksandrovich, master student of World History, Law and Methods of Teaching Department Samara State University of Social Sciences and Education (Samara, Russian Federation)

Abstract. This paper discusses the state of emergency imposed by the British in Malaya. The work in Malaya is based on the analytical work of the American RAND Corporation members. The Malaya conflict is successful for the British in the field of colonial knowledge. That is why the conflict was carefully studied by the RAND Corporation as a model of counter-insurgency; therefore, we can see the interest of the United States to the analysis and methods of struggle against the rebel movement before the era of the Vietnam conflict. Of course, RAND worked for the US government, i.e. the Ministry of defense has signed contracts with this Corporation. The United States will try to practice certain methods of fighting guerrillas in Vietnam, but it is worth considering that each conflict is individual. The paper shows the Communist movement evolution in Malaya - from the inception to the victory of the British and the gradual disappearance of the rebel movement. The conflict was successful for the UK, as the main population of Malaya was not interested in the departure of the British; the local elite supported the British crown. The paper demonstrates features of the Malay conflict.

Keywords: Malaya; RAND; British; guerrilla warfare; counterinsurgency war; decolonization; state of emergency; UK; USA; Chinese; partisans; Communist party of Malaya; Federation; Union; World War II; rubber; Soviet Union; colonial experience; insurgency; Malays.

\section{МИНИСТЕРСКИЕ РАЗНОГЛАСИЯ И ДАВЛЕНИЕ НА ГОСПЛАН В СОВЕТСКОЙ ЭКОНОМИКЕ В НАЧАЛЕ 1950-Х ГОДОВ}

(C) 2018

Захарченко Алексей Владимирович, доктор исторических наук, доцент, заведующий кафедрой истории, международного права и зарубежного регионоведения Самарский филиал Московского городского педагогического университета (2. Самара, Российская Федераџия)

Аннотаичя. В статье на основе архивных документов анализируется механизм выработки компромиссных решений при обсуждении плана развития народного хозяйства СССР на 1951-1955 гг. Анализ источников (записок руководителей министерств в правительство, справок Госплана и его проектов развития советской экономики на период 1951-1955 гг.) показывает наличие разногласий между центральным органом планирования и хозяйственными ведомствами. Позиция Госплана, который стремился к составлению сбалансированного плана, заключалась в распределении ресурсов и хозяйственных обязательств между министерствами. Министерства со своей стороны склонны были предлагать более низкие цифры роста производственных показателей и завышенные объемы ресурсов на выполнение планов. Расхождения в позициях регулировались специальной межведомственной комиссией по разногласиям, предложения которой брались за основу правительством и Госпланом для внесения поправок в текущее и перспективное планирование промышленного развития СССР. Результаты исследования позволяют сделать вывод о том, что плановая экономика в действительности являлась экономикой «согласований». В этой системе директивы правительства рассматривались как результат межведомственной борьбы «плановиков» и «производственников», в которой Госплан уравновешивал амбиции министерств. Однако активный «лоббизм» министров ограничивал возможности «плановиков», о чем свидетельствуют документы комиссии по разногласиям.

Ключевые слова: Советская экономика; Госплан; министерства; планирование; отраслевые отделы; пятый Совет Министров СССР; производительность труда; жилищное строительство; Министерство автотракторной промышленности; М.З. Сабуров; В.А. Малышев; пятый пятилетний план; ведомственные конфликты; комиссия по разногласиям. 
Госплан в советской хозяйственной системе играл ключевую роль не только как ведомство по разработке стратегии развития народного хозяйства. Он выполнял функцию согласования интересов министерств, служил институтом экспертной оценки потенциала отраслевых структур советской экономики с точки зрения их возможностей реализовывать плановые директивы. Госплан выступал важнейшим звеном в распределении фондов на экономические ресурсы. Их недостаток неизбежно вел к столкновению между собой хозяйственных «агентов» в лице министерств, отстаивающих перед Госпланом свои варианты выполнения производственного плана. Это порождало регулярные разногласия ведомств с центральным плановым органом как по вопросам объема ресурсов на выполнения хозяйственных обязательств, так и по вопросам корректировки производственных заданий. Исследовательская позиция заключается в том, что в рамках советской административно-командной системы в сталинскую эпоху существовали механизмы самонастройки, которые делали директивное планирование в определенной степени условным. Конкуренция ведомств за ресурсы и преференции для выполнения хозяйственных директив приводила к постоянным поправкам как в проекты планов, так и в уже утвержденную плановую документацию. Для регулирования министерских запросов и интересов Госплана, отстаивающего перед хозяйственными министерствами проекты годовых и перспективных планов, был отработан определенный механизм по разрешению разногласий через работу межведомственной комиссии. Изучение этого механизма и содержания конфликта интересов Госплана и министерств по вопросам планирования в период позднего сталинизма (вторая половина 1940 x - начало 1950-х) является целью данной статьи.

Основными источниками по данной проблематике послужили документы Госплана, хранящиеся в Российском государственном архиве экономики. В частности - материалы секретариата председателя Госплана, представленные справками о разногласиях с министерствами, альбомами с исправленными показателями проектов годовых планов, запросы министерств в правительственные инстанции, экспертные заключения отделов Госплана на такого рода запросы, протоколы межведомственной комиссии по разногласиям [1]. Совокупность указанных архивных материалов позволяет исследовать вопрос выработки механизма регулирования ведомственных интересов в рамках плановой экономики.

В историографии проблема межведомственной борьбы в политической системе власти СССР сталинской эпохи нашла отражение в трудах Р.Г. Пихои, О. Хлевнюка, Й. Горлицкого, В.П. Попова, А.А. Данилова, А.В. Пыжикова [2-6]. Авторы обращали внимание на период послевоенного развития СССР и определение советским руководством курса на дальнейшее усиление промышленного сектора экономики. Трудов, посвященных деятельности Госплана и его участию в разногласиях между хозяйственными агентами, не так много. Применительно к периодам 1930-х и второй половине 1950-х гг. отметим публикации Е.Б. Беловой и В.Л. Некрасова [7-9], в которых авторы исследуют институциональные аспекты функционирования плановой экономики. Таким об- разом, анализ основных направлений в историографии показал, что послевоенный период 1945-1953 гг. относительно роли Госплана в межведомственных отношениях при осуществлении экономической политики сталинским руководством пока еще мало исследован и требует более внимательного изучения и постановки новых проблем.

Для согласования интересов министерств в отношении проекта пятилетнего и годовых планов, предлагаемых Госпланом, при правительстве в начале 1950-х гг. действовала межведомственная комиссия по разногласиям. Туда входили руководители отраслевых бюро при Совете Министров СССР, министр финансов, председатель Госплана (он же председатель комиссии), руководители его профильных отделов. Начальник профильного отдела, курировавший планирование по определенной группе министерств, составлял для комиссии справку по разногласиям с Госпланом. После этого комиссия готовила поправки по каждому министерству. Итоговый документ по согласованию разногласий между министерствами и Госпланом направлялся в президиум Совета Министров СССР для принятия постановления, в котором плановики обязаны были внести поправки в плановые задания.

Исходя из содержания справок, можно говорить о том, что линия несовпадения позиций министерств и плановиков проходила по большинству параметров, касаясь производства как валовой, так и товарной продукции, освоения новых видов продукции, кооперированных поставок другим министерствам, выработки рабочих, фонда заработной платы, себестоимости, капитального строительства и т.д.

Архивные материалы фонда Госплана, посвященные обсуждению параметров пятой пятилетки (1951-1955 гг.), позволяют говорить о столкновении ведомственных интересов Госплана и министерств. Плановики выступали за более высокие показали для каждого министерства, будь то рост производительности труда, снижение себестоимости, рост производства товарной и валовой продукции. Министерства отстаивали свои цифры - ниже тех, что содержались в документах Госплана, и в то же время запрашивали больше фондов на материальные ресурсы. Общим правилом являлись и обращения в правительство с просьбами увеличить объем капиталовложений.

Поведение региональных хозяйственных руководителей и партийно-советской номенклатуры, выступавших за дополнительные преференции в сфере распределения фондов на экономическое развитие своих регионов так же являлось определенной проблемой для Госплана.

В октябре 1952 г. на XIX съезде были приняты директивные указания к пятому пятилетнему плану 1951-1955 гг. Его общие параметры были разработаны плановиками и утверждены высшим руководством. Однако по отдельным деталям делегатам съезда разрешено было высказать свои предложения. Их публиковали в центральной печати, а в систематизированном виде направили в ЦК КПСС. Оттуда материалы поступили в Госплан, где специалисты должны были дать свое обоснование высказанным предложениям [10, л. 95-141]. Для плановиков это была дополнительная нагрузка, поскольку приходи- 
лось отвлекать силы и время на ответы на откровенно популистские предложения. Как правило, советы делегатов съезда сводились к пожеланиям «расширить», «увеличить», «запустить новые стройки» и т.д. Некоторые рекомендации, которые давали по конкретным регионам, носили локальный характер, выходили за рамки хозяйственного баланса уже утвержденных цифр. Например, делегат от Ростовской области предложил в течение 3-4 лет пятилетки удвоить добычу угля в своем регионе. Однако, по мнению Госплана, такое количество угля превышало хозяйственные потребности промышленности. К тому же для увеличения добычи пришлось бы ввести дополнительные мощности на 30 млн. тонн [10, л. 95]. Отдельные рекомендации, касающиеся общего направления развития народного хозяйства, были просто бесполезны по той причине, что делегаты не были знакомы с содержанием пятилетнего плана по отдельным промышленным отраслям и уже принятым правительственным решениям. Так, в частности, делегаты предлагали выпуск продукции машиностроения и приборостроения для электровакуумной промышленности увеличить в 3-4 раза. В то же время в проекте плана на 1951-1955 гг. предусматривалось увеличение по Министерству промышленности средств связи выпуск специального технологического оборудования для электровакуумной промышленности в 14,7 раза. Кроме того, постановлением Совета Министров СССР от 14 сентября 1951 г. на ряд министерств уже был возложен выпуск этого оборудования [10, л. 95].

В декабре 1952 г. отделы и управления Госплана направили результаты работы над проектами делегатов председателю планового органа М.3. Сабурову. Некоторые рекомендации были учтены. Причем это касалось и оборонных отраслей. 22 декабря 1952 г. заместитель начальника управления военной промышленностью Госплана В. Румянцев также направил материалы с отклоненными и принятыми рекомендациями.

Одним из важнейших направлений хозяйственной деятельности экономических министерств являлось капитальное строительство. Как правило, разногласия в этом случае возникали относительно выделения необходимых фондов. Помимо этого, министерства в отдельных случаях старались оградить себя от обязательств по новому объекту, ссылаясь на напряженную программу. Так, в 1950 г. возникли разногласия между Министерством внутренних дел и Министерством металлургической промышленности по вопросам строительства химического цеха Московского комбината твердых сплавов. Министерство металлургической промышленности настаивало, чтобы цех строило МВД, однако получило категорический отказ. Госплан вынужден был согласиться с позицией органов внутренних дел. В итоге работы возложены на Министерство строительства тяжелой промышленности [11, л. 69].

Существенные разногласия Госплана с министерствами наметились в процессе обсуждения проекта пятилетнего плана развития народного хозяйства на 1951-1955 гг. [10]. Руководители ведомств направляли письма в Госплан и правительство (их разбирали в отраслевых бюро под председательством заместителей Сталина в правительстве), стараясь умень- шить объем хозяйственных обязательств, которые составляли плановики. Причем и плановики, и руководители министерств в идеале выступали за более сбалансированный, с их точки зрения, проект плана. Так, в октябре 1951 г. Министерство бумажной и деревообрабатывающей промышленности заявило о том, что «не может согласиться с предложением Госплана и Госснаба по объемам выработки целлюлозы и бумаги, предлагаемые на 1952 г.» [12, л. 52]. В министерстве отмечали, что его предприятия на Дальнем Востоке не обеспечены древесиной, целлюлозно-бумажным комбинатам недостаточно электроэнергии, мебельные предприятия срывают производство мебели, поскольку не получают в должном количестве сырья [12, л. 52]. Ряд требований отражал исключительно ведомственные интересы, связанные с желанием снять с себя некоторые производственные обязательства, в то же время получить дополнительные ресурсы. В частности, Госплану предлагалось освободить Министерство бумажной и деревообрабатывающей промышленности от изготовления 15000 кузовов для автомобиля «Москвич», поскольку это «простейшее изделие деревообработки может изготовляться любой артелью местной промышленности, а загружать Министерство такой продукцией в ущерб производству радиокузовов нерационально» [12, л. 53]. В Министерстве также просили установить план оргнабора рабочей силы в 1952 г. в количестве 15000 человек («т.е. хотя бы на уровне 1951 г.»), и пересмотреть процент снижения себестоимости продукции с 6,6\% (по проекту Госплана) до $6,6 \%$ [12, л. 53]. Однако возражения Министерства бумажной и деревообрабатывающей промышленности не нашли поддержки ни в Госплане, ни в межведомственной комиссии, где позиции плановиков были также сильны. Об этом свидетельствуют материалы комиссии по разногласиям, направленные в Президиум Совета Министров СССР [12, л. 1-7].

Одним из «камней преткновения» стали вопросы финансирования и определения итоговых цифр по производственным показателям. Согласно данным, представленным 25 марта 1952 г. начальником отдела Городского хозяйства Госплана СССР А. Шаровым, при распределении объемов жилищного строительства министерства заложили на 1951-1955 гг. более высокие позиции, чем Госплан (табл. 1).Такое единодушие по увеличению плановых объемов строительства со стороны министерств диктовалось, по всей видимости, их стремлением получить фонды на жилищное строительство для своих работников в большем объеме.

Совершенно противоположную реакцию вызвал проект плана на 1951-1955 гг. в частях, касающихся роста производительности труда, хозяйственных обязательств по увеличению выпуска продукции, снижению ее себестоимости. Ведомственные интересы в данном случае проявились в том, что министерства предлагали контрольные цифры ниже, чем Госплан (табл. 2).

Согласно справке о разногласиях, составленной начальником управления планирования труда и зарплаты Госплана Б. Безруковым по проектам министерств, рост производительности труда в 19511955 гг. у рабочих промышленности должен был составить 45\% в 1955 г. по сравнению с 1950-м, а Госплан предлагал цифру роста в $51 \%$ [10, л. 63]. 
Таблица 1 - Проект пятилетнего плана по жилищному строительству в 1951-1955 гг. (выборочно по союзным министерствам) [1, оп. 97, д. 484, л. 63]

\begin{tabular}{|l|c|c|}
\hline \multirow{2}{*}{ Министерства } & \multicolumn{2}{|c|}{$\begin{array}{c}\text { Ввод в действие жилой площа- } \\
\text { ди на 1951-1955 гг., тыс. } \text { М }^{2}\end{array}$} \\
\cline { 2 - 3 } & $\begin{array}{c}\text { Проект } \\
\text { Госплана }\end{array}$ & $\begin{array}{c}\text { Проект } \\
\text { министерств }\end{array}$ \\
\hline $\begin{array}{l}\text { Министерство } \\
\text { авиационной } \\
\text { промышленности }\end{array}$ & 1330 & 1600 \\
\hline $\begin{array}{l}\text { Министерство } \\
\text { судостроительной } \\
\text { промышленности }\end{array}$ & 1550 & 1420 \\
\hline $\begin{array}{l}\text { Министерство } \\
\text { обороны }\end{array}$ & 2700 & 5500 \\
\hline $\begin{array}{l}\text { Военно-морское } \\
\text { министерство }\end{array}$ & 1075 & 1600 \\
\hline
\end{tabular}

Таблица 2 - Планируемый в 1955 г. рост производительности труда (к 1950 г.) [13, л. 63]

\begin{tabular}{|l|c|c|}
\hline \multicolumn{1}{|c|}{ Министерства } & $\begin{array}{c}\text { Проект } \\
\text { Госплана }\end{array}$ & $\begin{array}{c}\text { Проект ми- } \\
\text { нистерств }\end{array}$ \\
\hline $\begin{array}{l}\text { Министерство нефтяной } \\
\text { промышленности }\end{array}$ & $38,4 \%$ & $16,6 \%$ \\
\hline $\begin{array}{l}\text { Министерство автотрак- } \\
\text { торной промышленности }\end{array}$ & $50 \%$ & $40 \%$ \\
\hline $\begin{array}{l}\text { Министерство станко- } \\
\text { строения }\end{array}$ & $74,4 \%$ & $59 \%$ \\
\hline $\begin{array}{l}\text { Министерство судострои- } \\
\text { тельной промышленности }\end{array}$ & $79,5 \%$ & $68,7 \%$ \\
\hline
\end{tabular}

Каждое министерство предлагало цифры, пусть и в незначительной степени, но все-таки расходившиеся с предложениями Госплана. Министерство угольной промышленности предлагало установить на 1955 г. среднемесячную добычу угля на 1 рабочего в 40 тонн, а Госплан предложил цифру в 42 тонны. Планируемая вывозка леса по Министерству лесной промышленности составляла на 1 рабочего $225 \mathrm{~m}^{3}$, плановики увеличили ее до $240 \mathrm{~m}^{3}$. Сами министры в многочисленных обращениях в правительство и Госплан старались скорректировать предлагаемые плановиками хозяйственные обязательства министерств в сторону сокращения. Активным ведомственным «лоббистом», оспаривавшим предложенные Госпланом проектные цифры, являлся министр автотракторной промышленности В.А. Малышев. Обладая авторитетом и серьезным административным опытом (в годы войны он возглавлял Наркомат танковой промышленности), В.А. Малышев располагал значительным аппаратным ресурсом. Помимо министерской должности он входил в состав Президиума Сoвета Министров СССР, что позволяло ему через правительство оказывать давление на Госплан, добиваясь пересмотра завышенных, с его точки зрения, планов.

В комиссию по разногласиям поступили материалы из Госплана, в которых отмечалось, что Малышев настаивал на пересмотре плановых показателей в 1952 г. Он настаивал на двукратном сокращении плана производства по стальной арматуре для Министерства автотракторной промышленности (Госплан в своем проекте предлагал цифру в 6000 тонн), на сокращении, правда незначительном, выпуска вело- сипедов [12, л. 207]. Наконец, В.А. Малышев считал целесообразным исключить из проекта плана производство 25-ти модернизированных легковых автомобилей «Москвич» и изготовление специального агрегата для производства биметаллической ленты для вкладышей подшипников двигателей. После рассмотрения этих материалов на комиссии по разногласиям 9 ноября 1951 г. замечания В.А. Малышева были учтены [15, л. 11]. Однако плановики противостояли ведомственному давлению, и каждую позицию министерствам приходилось «выбивать», о чем свидетельствуют справки о результатах рассматриваемых разногласий 3 октября 1951 г. (таблица 3). Так, Министерство автотракторной промышленности, по итогам обсуждения производственного плана на 1952 г., не смогло добиться преференций по всем позициям выпуска запчастей к тракторам. Учитывая, что комиссию по разногласиям возглавлял председатель Госплана М.3. Сабуров, возможности министерств в спорах с плановиками через данный канал были ограниченны. Содержание данной справки позволяет говорить об очередном компромиссе - отстояв одни цифры, плановики уступили ведомству В.А. Малышева в других.

Таблица 3 - Справка межведомственной комиссии М.3. Сабурова о результатах рассмотренных разногласий с Министерством автотракторной промышленности на 1952 г. (составлено по [14, л. 208])

\begin{tabular}{|c|c|c|c|c|}
\hline $\begin{array}{c}\text { Согласованные } \\
\text { поправки }\end{array}$ & $\begin{array}{l}\text { Ед. } \\
\text { изм. }\end{array}$ & $\begin{array}{l}\text { Про- } \\
\text { ект } \\
\text { Гос- } \\
\text { плана }\end{array}$ & $\begin{array}{l}\text { Предло- } \\
\text { жения } \\
\text { мини- } \\
\text { стерства }\end{array}$ & $\begin{array}{c}\text { Предла- } \\
\text { гается } \\
\text { принять }\end{array}$ \\
\hline $\begin{array}{l}\text { Запчасти к } \\
\text { трактору «Уни- } \\
\text { версал»: } \\
\text { a) блок-картер }\end{array}$ & $\begin{array}{c}\text { тыс. } \\
\text { шт. }\end{array}$ & 5 & 3 & 5 \\
\hline $\begin{array}{l}\text { Запчасти к трак- } \\
\text { тору СХТЗ- } \\
\text { НАТИ: } \\
\text { а) звено } \\
\text { гусеницы } \\
\text { б) колесо } \\
\text { ведущее }\end{array}$ & $\begin{array}{l}\text { тыс. } \\
\text { шт. } \\
\text { тыс. } \\
\text { шт. }\end{array}$ & $\begin{array}{l}10800 \\
260\end{array}$ & $\begin{array}{l}9500 \\
200\end{array}$ & $\begin{array}{c}10500 \\
230\end{array}$ \\
\hline $\begin{array}{l}\text { Запчасти к } \\
\text { трактору ДТ-54: } \\
\text { а) гильза } \\
\text { цилиндра } \\
\text { б) шестерня } \\
\text { ведущая } \\
\text { в) шестерня } \\
\text { ведомая }\end{array}$ & $\begin{array}{l}\text { тыс. } \\
\text { шт. } \\
\text { тыс. } \\
\text { шт. } \\
\text { тыс. } \\
\text { шт. }\end{array}$ & $\begin{array}{l}330 \\
75\end{array}$ & $\begin{array}{l}250 \\
50 \\
25\end{array}$ & $\begin{array}{l}250 \\
50 \\
25\end{array}$ \\
\hline
\end{tabular}

В конечном итоге количество претензий от министерств, руководства союзных республик к Госплану привело к многочисленным поправкам в проект плана на 1952 г. Результатом компромисса стало письмо в Президиум Совета Министров СССР от 2 ноября 1951 г. за подписью председателя комиссии по разногласиям М.3. Сабурова о принятых поправках в проект плана на 1952 г. по промышленности [15, л. 1-7].

В итоге снижения хозяйственных обязательств добилось Министерство пищевой промышленности. Так, план по улову рыбы был снижен министерству на 72 тыс. тонн, по производству колбасных изделий 
- на 15 тыс. тонн, сахара-песка - на 45 тыс. тонн, масла растительного - на 25 тыс. тонн. Сокращение производственной программы удалось получить предприятиям промышленности строительных материалов: план выпуска цемента снизили на 190 тыс. тонн, кирпича - на 269 млн. шт., заменителей кирпича - на 293 млн. шт. [15, л. 1-4]. Были учтены просьбы руководства топливных министерств. В угольной промышленности произошло перераспределение плановых заданий по добыче коксующихся углей разных марок в Донецком и Кузнецком угольных бассейнах. Вопрос об увеличении рабочей силы также был решен в пользу министерств. Всего численность рабочих и служащих в народном хозяйстве планировалось увеличить в 1952 г. до 41,3 млн. человек, или на 120 тыс. человек больше, чем предлагал Госплан. Если Госплан настаивал на цифре 15 тыс. человек, которых планировалось принять по оргнабору в Министерство строительства предприятий тяжелой индустрии, то комиссия поддержала данное министерство и рекомендовала увеличить в проекте плана 1952 г. оргнабор до 20 тыс. человек [15, л. 6-7].

Таким образом, на примере обсуждения параметров пятой пятилетки 1951-1955 гг. можно говорить о выработке механизма согласования ведомственных интересов. Деятельность комиссии по разногласиям позволяла достигать определенного уровня компромисса, регулировать конфликты министерств с Госпланом, представляя в правительство выработанные проекты решений. Анализ архивных материалов позволяет говорить о сложившейся в советской директивной экономике практике давления на Госплан со стороны хозяйственных министерств, которым плановики противостояли с переменным успехом. Принадлежность к оборонной отрасли и особое место в высших государственных структурах, как это видно на примере В.А. Малышева, могли усиливать эффект министерского давления, способствовали получению выгодных преференций для реализации плановых директив.

\section{DISAGREEMENTS AMONG MINISTRIES AND PRESSURE \\ ON THE STATE PLANNING COMMITTEE IN THE SOVIET ECONOMY IN THE EARLY 1950S}

(C) 2018

\section{Список литературы:}

1. Российский государственный архив экономики (РГАЭ). Ф. 4372 / Государственная плановая комиссия при Совете Министров СССР. Оп. 97-99.

2. Пихоя Р.Г. Советский Союз: история власти. 1945-1991. Новосибирск: Изд-во «Сибирский хронограф», 2000. $684 \mathrm{c}$.

3. Попов В.П. Экономическая политика советского государства. 1946-1953 гг. М.-Тамбов: Изд-во Тамбов. гос. ун-та, 2000. 222 с.

4. Хлевнюк О.В. Советская экономическая политика на рубеже 1940-1950-х гг. и «дело Госплана» // Отечественная история. 2001. № 3. С. 77-89.

5. Хлевнюк О.В., Горлицкий Й. Холодный мир: Сталин и завершение сталинской диктатуры. М.: РОССПЭН, 2011. $231 \mathrm{c}$.

6. Данилов А.А., Пыжиков А.В. Рождение сверхдержавы: СССР в первые послевоенные годы. М.: РОССПЭН, 2001. 304 c.

7. Белова Е.Б. Стихия плана: практика работы Госплана СССР в первой половине 30-х гг. // Экономическая история: Ежегодник. 2001. М., 2002. С. 579-606.

8. Некрасов В.Л. Реформа Госплана СССР 1955 г.: разработка новой модели планирования экономики // Вестник ТГУ. 2013. № 368. С. 99-103.

9. Некрасов В.Л. Должность председателя Госплана СССР в системе высшего политического руководства (1955-1964 гг.) // Гуманитарные науки в Сибири. 2012. № 4. С. 66-69.

10. РГАЭ. Ф. 4372. ОП. 97. Д. 484.

11. РГАЭ. Ф. 4372. ОП. 97. Д. 116.

12. РГАЭ. Ф. 4372. ОП. 99. Д. 127.

13. РГАЭ. Ф. 4337. Оп. 97. Д. 484.

14. РГАЭ. Ф. 4372. ОП. 99. Д. 147.

15. РГАЭ. Ф. 4372. ОП. 99. Д. 197.

Статья подготовлена при финансовой поддержке РФФИ (проект «Госплан и межведомственные отночения в контексте экономической политики СССР в послевоенный период (19451953)» № 16-01-50017).

\author{
Zaharchenko Alexey Vladimirovich, doctor of historical sciences, associate professor, \\ head of History, International Law and Foreign Regions Studies Department \\ Samara Branch of Moscow City Pedagogical University (Samara, Russian Federation)
}

\begin{abstract}
The following paper deals with mechanisms for working out compromise solutions when discussing the plan for the USSR national economy development in 1951-1955. The sources analysis (notes of ministries heads to the government, the Gosplan's reports and its projects for the development of the Soviet economy for the period 1951-1955) shows there were disagreements between the central planning body and the economic agencies. The position of the State Planning Committee, which sought to draw up a balanced plan, consisted in the allocation of resources and economic obligations between ministries. The ministries, for their part, were inclined to offer lower figures for the growth of production indicators and overestimated amounts of resources to implement the plans. Divergences in positions were regulated by a special interdepartmental commission on disagreements, its proposals were taken as a basis by the government and the State Planning Committee to amend the current and future planning of the industrial development of the USSR. The results of the study allow us to conclude that the planned economy was actually the economy of «approvals». In this system, government directives were viewed as a result of an interagency struggle between «planners» and «production workers», where the State Planning Committee counterbalanced the ambitions of ministries. However, active «lobbyism» of ministers limited the possibilities of «planners», as evidenced by the documents of the Dispute Commission.

Keywords: Soviet economy; Gosplan; ministries; planning; branch departments; Council of Ministers of USSR; labor productivity; housing construction; Ministry of Automotive and Tractor Industry; M.Z. Saburov; V.A. Malyshev; five-year plan; departmental conflicts; Dispute Commission.
\end{abstract}

